\title{
Elevated lactic acid during ketoacidosis: pathophysiology and management
}

\author{
Hamda Houssein Ahmed, David De Bels, Rachid Attou, \\ Patrick M. Honore, Sebastien Redant
}

Intensive Care Unit, CHU Brugmann, Free University of Brussels ULB (ULB), Brussels, Belgium

\begin{abstract}
Lactic acidosis results from an acid-base balance disorder of the body due to an excess of lactic acid. It is frequently found in critically ill patients admitted to the intensive care. The most common cause is type A, found in pathologies such as cardiogenic, septic and hypovolemic shock, trauma and severe hypoxemia. The type B is less common and arises without evidence of tissue hypoperfusion or shock. Divers etiologies have been described for this type of hyperlactatemia: Grand Mal seizures, liver failure, hematologic malignancies, congenital enzyme deficiencies, thiamine deficiencies and diabetes mellitus and also alcohol abuse, which may induce a lactic acid under-use or an increased production. The authors describe a rare complication of type 1 Diabetes Mellitus (T1DM), leading to a major and persistent expression of a type $B$ lactic acidosis during ketoacidosis.
\end{abstract}

Key words: glycogenic hepatopathy, Mauriac syndrome, ketoacidosis, lactic acidosis

\section{INTRODUCTION}

Lactic acidosis results from an acid-base balance disorder of the body due to an excess of lactic acid. It is frequently found in critically ill patients admitted to the intensive care. The most common cause is type $A$, found in pathologies such as cardiogenic, septic and hypovolemic shock, trauma and severe hypoxemia. Type B is less common and arises without evidence of tissue hypoperfusion or shock. ${ }^{[1]}$ Divers etiologies have been described for this type of hyperlactatemia: Grand Mal seizures, liver failure, hematologic malignancies, congenital enzyme deficiencies, thiamine deficiencies and diabetes mellitus, ${ }^{[1]}$ and also alcohol abuse, which may induce a lactic acid under-use or an increased production. ${ }^{[2,3]}$ The authors describe a rare complication of type 1 Diabetes Mellitus (T1DM), leading to a major and persistent expression of a type $B$ lactic acidosis during ketoacidosis.

Rationale of the study: The author would like to report a rare clinical entity that could bring a message to the scientific community.

\section{CASE PRESENTATION}

A 16-year-old female patient diagnosed T1DM from the age of 6 , complaining about fever at $38.5^{\circ} \mathrm{C}$ and diarrhea, was admitted to the emergency room. She reduced her food intake and stopped her insulin therapy. Her glycemia was rated at $47.7 \mathrm{mmol} / \mathrm{L}$; anion gap of 44.5 and lactate reached $3.22 \mathrm{mmol} / \mathrm{L}$. Urine test was positive for ketones. Her glycated hemoglobin A1C concentration was 10.7\%, which revealed a non-optimal glucose control. She was admitted to the intensive care for management of diabetic keto acidosis (DKA).

Clinically, the patient had no signs of shock, was hemodynamically stable with a slight polypnea and a normal facies. Weight was $66.3 \mathrm{~kg}$ (P75) and height was $165 \mathrm{~cm}$ (P90). The abdomen palpation has shown a hepatomegaly.

Blood glucose level was $3.8 \mathrm{mmol} / \mathrm{L}$ with 3 $\mathrm{UI} / \mathrm{h}$ insulin infusion. Total serum bilirubin was $0.4 \mathrm{mg} / \mathrm{dL}$, aspartate aminotransferase 
(AST) $38 \mathrm{UI} / \mathrm{L}$, alanine aminotransferase (ALT) $40 \mathrm{UI} / \mathrm{L}$, alkaline phosphatase $195 \mathrm{UI} / \mathrm{L}$, lactic acid $4.22 \mathrm{mmol} / \mathrm{L}$, total cholesterol of $298 \mathrm{mg} / \mathrm{dL}$ and triglyceride $1184 \mathrm{mg} /$ dL.

Ultrasonography confirmed a liver enlargement, with regular contours and a homogeneous echo structure. Arterial blood assessment highlighted a constant lactic acidosis regardless of insulin and dextrose infusion (Figure 1). On the third day, the patient was transitioned to subcutaneous insulin and her last lactate rate was $13.43 \mathrm{mmol} / \mathrm{L}$ (Figure 1). No hepatic auto antibodies, no viral hepatitis, or fan antibodies were found. Immunological and celiac diseases were also excluded. Nonetheless, a subclinical hypothyroidism was revealed. Electromyography was normal (no neuropathy, or myopathy). Hepatic biopsy showed a hepatic glycogen overload with fibrous frame. In front of an uncontrolled diabetes type 1, hepatomegaly, glycogenic hepatopathy and persistent hyperlactatemia, a diagnosis of Mauriac syndrome was made. The patient left the hospital with a basal prandial insulin schema. Her ratio lactate/pyruvate was above 30 . Three months later, lactate was $4.81 \mathrm{mmol} / \mathrm{L}$.

\section{DISCUSSION}

Mauriac, in $1930,{ }^{[4]}$ described a syndrome in a young diabetic type 1 patient with poor glycemic control. It is characterized by excessive glycogen storage called glycogen hepatopathy associated with growth retardation, delayed puberty and cushingoid features. Nowadays, in adults with T1DM, we know that hepatic defects outcoming in Mauriac syndrome can be observed without the entire syndromal features. ${ }^{[5-7]}$ In T1DM with poor glycemic control, two major events occur: hyperglycemia and high dose insulin administration. In hyperglycemia, glucose freely diffusing through the insulin-independent GLUT2 transporter, is phosphorylated then converted to glucose-6-phosphate (G6P); and so, it cannot leave the hepatocyte. Increased insulin administration lead to the G6P conversion into glycogen by the glycogen-synthase. ${ }^{[8]}$ The hyperglycemia and simultaneous high levels of insulin used as treatment of diabetic ketoacidosis induce an increased risk for hepatic glycogen overload bringing out afterwards lactic acidosis. Jeppensen et al. have studied the lactate splanchnic uptake and his metabolism during gluconeogenesis. They discovered a significant raised fasting lactate level linked to portal pressure and excretory liver function in patients with chronic hepatic disease compared to the control group. However, enhanced splanchnic lactate production was highlighted in both groups after ingestion of a meal or galactose. Their results revealed a lactate production beneath wellperfused and well-oxygenated conditions. Lactate level reduces by hepatic gluconeogenesis with no significant renal production or elimination of lactate has also been demonstrated. ${ }^{[9]}$

In Mauriac Syndrome, impaired gluconeogenesis and a defect of pyruvate to glucose conversion could be accounted for the lactic acidosis observed. ${ }^{[1]}$ During adulthood, the Mauriac syndrome is suspected in the presence of hepatomegaly, abdominal pain, nausea and vomiting. Laboratory findings are high levels of glucose, hemoglobin glycated concentration (HBA1C), AST and

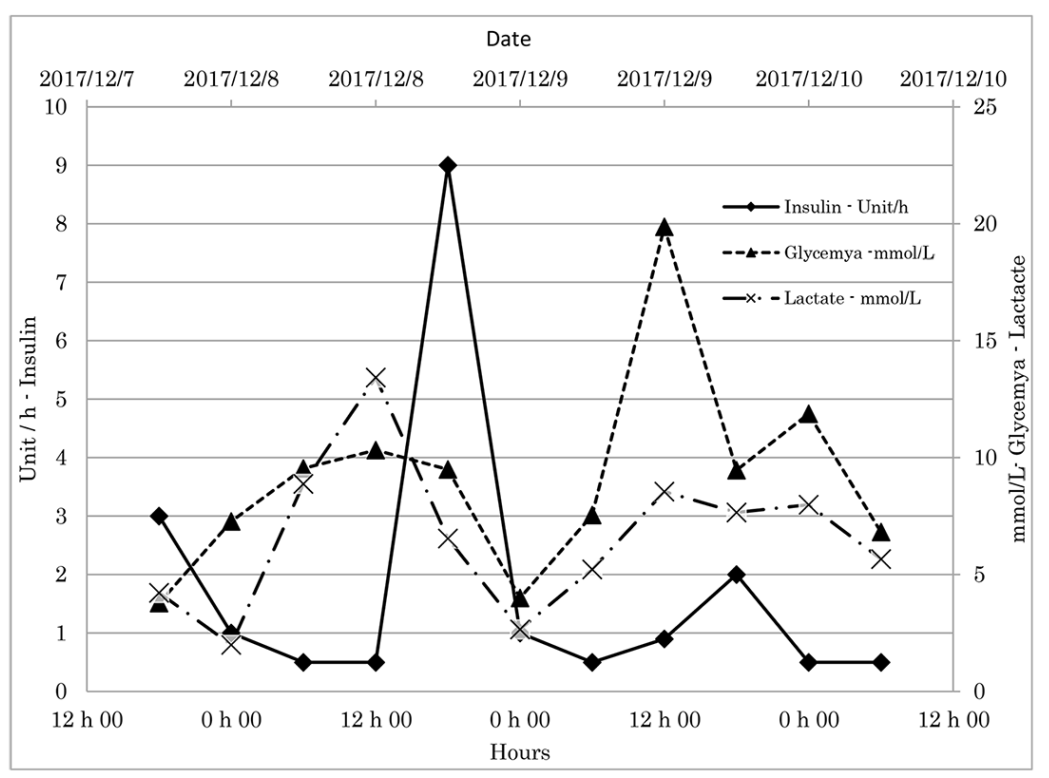

Figure 1: Serial measurements of lactate and glycemia over 3 days of dextrose and insulin therapy 
ALT. ${ }^{[8]}$ The differential diagnosis includes infectious disease, metabolic (Wilson disease, hemochromatosis) obstructive or oncologic causes as well as autoimmune hepatitis. Treatment involves improving blood glucose and HbA1C. ${ }^{[1]}$ Decreased symptoms, liver enzymes level and hepatomegaly have been demonstrated with minor improvement to HbA1C. ${ }^{[10]}$

\section{LIMITATION OF THE STUDY}

We were unable to make an in-depth analysis using the cases of the literature due to lack of reports in the literature and the absence of control group in those reports. We had to limit ourselves to a single center descriptive study.

\section{CONCLUSION}

Mauriac Syndrome is a rare complication of poorly controlled T1DM and is still under-diagnosed. Clinical signs composing this syndrome are frequently incomplete and lactic acidosis could be exacerbated by high doses of insulin and glucose therapy as seen during the ketoacidosis management.

\section{Conflict of Interests}

The authors declare having no competing interests.

\section{REFERENCES}

1. Deemer KS, Alvarez GF. A rare case of persistent lactic acidosis in the ICU: glycogenic hepatopathy and Mauriac Syndrome. Case Rep Crit Care 2016; 2016: 6072909.

2. van den Nouland DP, Brouwers MC, Stassen PM. Prognostic value of plasma lactate levels in a retrospective cohort presenting at a university hospital emergency department. BMJ Open 2017; 30: e011450.

3. Kraut JA, Madias NE. Lactic Acidosis. N Engl J Med 2014; 371:2309-19.

4. Mauriac P. Gros ventre, hepatomegalie, troubles de la croissance chez diabétiques traités depuis plusieurs années par insuline. Gax Hebd Med Bordeaux 1930; 26: 402-10.

5. van den Brand M, Elving LD, Drenth JP, van krieken JH. Glycogenic hepatopathy: a rare cause of elevated serum transaminases in diabetes mellitus. Neth J Med 2009; 67: 394-6.

6. Torbenson M, Chen YY, Brunt E, Cummings OW, Jakate S, Liu YC et al. Glycogenic hepatopathy: an underrecognized hepatic complication of diabetes mellitus. Am J Surg Pathol 2006; 30: 508-13.

7. Chatila R, Chest AB. Hepatomegaly and abnormal liver tests due to glycogenosis in adults with diabetes. Medicine (Baltimore) 1996; 75: 327-33.

8. Giordano S, Martocchia A, Toussan L, Stefanelli M, Pastore F, Devito A et al. Diagnosis of hepatic glycogenosis in poorly controlled type 1 diabetes mellitus. World J Diabetes 2014; 5: 882-8.

9. Jeppesen JB, Mortensen C, Bendtsen F, Moller S. Lactate metabolism in chronic liver disease. Scand J Clin Lab Invest 2013; 73: 293-9.

10. Parmar N, Altiq M, Austin L, Miller RA, Smyrk T, Ahmed K. Glycogenic hepatopathy: thinking outside the box. Case Rep Gastroenterol 2015; 9: 221-6.

How to cite this article: Ahmed HH, De Bels D, Attou R, Honore PM, Redant S. Elevated lactic acid during ketoacidosis: pathophysiology and management. J Transl Int Med 2019; 7: 115-7. 